\title{
EXPERIMENTAL INVESTIGATION OF INDIRECT EVAPORATIVE COOLER USING CLAY PIPE
}

\author{
R.Ramkumar ${ }^{1, *}$ A. Ragupathy ${ }^{1}$ \\ Keywords: Evaporative cooler, Relative humidity, Porosity, Clay pipe, Effectiveness, Aligned, Staggered
}

\begin{abstract}
The aim of the experimental study is to investigate the performance of indirect evaporator cooler in hot and humid regions. A novel approach is implemented in the cooler using clay pipe with different orientation as aligned and staggered position for potential and feasibility study. The clay pipe is the ceramic material where the water filled inside the tube and due to the property of porosity, the water comes outer surface of the tube and contact with the air passing over the tube and air get cooled. A test rig was designed and fabricated to collect experimental data. The clay pipes were arranged in aligned and staggered position. In our study heat transfer was analyzed with various air velocity of $1 \mathrm{~m} / \mathrm{s}$ to $5 \mathrm{~m} / \mathrm{s}$. The air temperature, relative humidity, pressure drop and water evaporation rate were measured and the performance of the evaporative cooler was evaluated. The experimental results were compared with mathematical values. The analysis of the data indicated that cooling effectiveness improve with decrease of air velocity at staggered position. It was shown that staggered position has the higher performance $(53 \%)$ at $5 \mathrm{~m} / \mathrm{s}$ air velocity in comparison with aligned position. The experimental of heat and mass transfer coefficients were compared with Colburn heat and mass transfer group. The test results were within the limit of $20 \%$ of mathematical values.
\end{abstract}

\section{INTRODUCTION}

For better human comfort, living or work environment is vital in tropical climates. Evaporative cooling process remains one of the least expensive techniques, environmentally clean, fresh supply air and natural fragrance of air, to bring dry bulb temperature to a more comfortable range, during hot season since ancient time. Evaporative cooling is based on the thermodynamic process of evaporating water to the surrounding air, which involves exchange sensible heat and latent heat between air and exposed water surface at constant enthalpy. However, changing liquid water to vapour adds moisture to the air flow by Lazzarin, Lain and Hensen, Gates et al. [1-3]. A common method of direct evaporative cooling for buildings can be found in many parts of Middle East countries including ancient Persian architect century and in Egypt in the form of 'Maziara jar' which consists of window screens that were built with holes or niches for water jars. The airflow around the porous jars evaporates the water and depresses its temperature. Evaporative coolers can be classified into two main categories, direct and indirect evaporative cooling system by Santamouris [4]. Direct evaporative cooling (DEC) is widely used in hot and dry climates for cooling purposes. In its primitive forms, a wet surface clay pot is used for cooling water and food while a wet mat hanging over a door or window through which hot outside air is blown into the building. Heat from the air is then absorbed by the water as it evaporates from the porous wetting medium, lowering its temperature by Abbouda and Almuhanna [5].

Researchers are encouraged to develop alternative cooling technology due to ozone depleting substances and greenhouse effect by the $\mathrm{CO}_{2}$ emission and other economic factors by Jodi.et.al.[6].The cooling technology will affect directly the energy cost and impact on the environment. It is estimated that average of about $60 \%$ of energy is consumed only for air conditioning and it has reached maximum $80 \%$ during at peak time by Al.Asad,Emtairah [7]. Globally, the market for air conditioning in buildings is dominated by mechanical vapor compression systems severe environmental impact related to the increased $\mathrm{CO}_{2}$ emission, the ozone-depleting Chloro Fluro Carbons (CFCs) and localized urban heat islands. In addition, these cooling systems are often linked to health problems affecting work productivity and mental well-being leading to a sharp rise in health complaints such as asthma by Harris [8]. Concerns

This paper was recommended for publication in revised form by Regional Editor Hafiz Muhammad Ali

${ }^{1}$ Department of Mechanical Engineering, Annamalai Univeristy, Annamalai Nagar-608002, Tamilnadu, India

*E-mail address: rrramkumar_hai@yahoo.com 
over global warming and the environmental damage caused by CFC refrigerants have stimulated research to develop alternate systems for air conditioning. One such system is based on evaporative cooling. This technique eliminates environmental damage and offers energy savings in running costs by Riangvilaikul and Kumar, Daou et al. [9-10].

Among the various methods of evaporative cooling, indirect evaporative cooling has been used widely in industrial and commercial air conditioning by Joudi and Mehdi, Suri [11,12] not only because it operates at very low energy cost, but also because it cools the air without adding moisture to it. This cooling technique eliminates environmental damage and offer energy saving in running cost. This technique is becoming popularly utilized in the world as an alternative of air conditioning by Costelloe and Finn, Gasparella and Longo [13, 14]. Porous ceramic evaporative cooling is a new technology which utilizes the evaporative cooling technique in building cooling, water desalination, juice concentration and other application by Ibrahim et.at, Kopellovich, Loeb and Johnson et.al [15-17]. An indirect evaporative cooler incorporating a porous ceramic and a heat pipe was describe by Riffa and Zhu[18]. Experiments were carried out to examine the effects of various ceramic properties, such as porosity, wall thickness, and outside diameter. Use of the cooler for a chilled ceiling in an environmental chamber was also investigated. A temperature drop of 3.8C per square meter of ceramic surface area was achieved for an $18 \mathrm{~m}$ chamber.

Modeling of an indirect evaporative cooling system for supply of sub wet bulb air temperature using porous ceramic materials was carried out by Meryem Kanzari et al. [19]. Results of the proposed design is capable of cooling air to temperatures lower than the ambient wet bulb temperature and achieving wet bulb effectiveness of about 1.17. An experimental study is conducted to cool ambient air for gas turbine inlet air cooling using ceramic tubes membrane by O. Zeitoun et.al [20]. Results show that using the modified ceramic tubes enhances the heat transfer between the air and water vapor. This enhancement is reflected by a maximum and minimum temperature drop of $11 \AA^{\circ} \mathrm{C}$ and $4{ }^{\circ} \mathrm{C}$ of the dry air. The wet media used in evaporative coolers is an essential component of an evaporative cooler. It is usually made of a porous material with large surface area and capacity to hold liquid water. According to Wanphen and Nagano [21], the selection of wet media materials is based on their effectiveness, availability, cost, safety, and environment factors.

Al-Fahed.el.al., [22] investigated the pottery evaporative cooling system of a novel approach to cool inlet air with minimal change in relative humidity and low water consumption. An experimental investigation tested two different unglazed pottery arrangements, aligned and staggered, under dry and wet conditions. From the results, relative humidity increases across the potteries, in the range of 2 to $5 \%$, and tends to be almost constant as air flow rate increases. Chen [23] studied cooling performance of a wet porous evaporative plate. Results showed that a porous evaporation cooling plate can achieve a $5-8^{\circ} \mathrm{C}$ drop in air temperature and that both a higher evaporation rate and vapor velocity occurred at lower values of ambient relative humidity and at higher values of ambient temperature. Evaporative cooling of water in a small porous clay vessel was studied under controlled humidity conditions by Ashutosh Mittal.et.al [24]. In steady-state experiments performed at an ambient temperature of $23{ }^{\circ} \mathrm{C}$, the cooling effect increased from 4.7 to $8.3{ }^{\circ} \mathrm{C}$ as the ambient relative humidity decreased from 60 to $15 \%$. Aimiuwu [25-27] found the long-term temperature of water in a porous ceramic pot to be $10.4-15^{\circ} \mathrm{C}$ below the ambient temperature and to have a smaller daily variation than the external temperature. Kam et al. [28] conducted a studies on hydrothermal transfer in porous terracotta tube, in hot, dry climate of the cooling of a water reserve and the room temperature is reduced to $15^{\circ} \mathrm{C}$ in the sahelian zone.

There is very limited research conducted on the pottery evaporative cooling system from the literature review. In this experimental study, a novel approach is conducted in evaporative cooler using clay pipes with orientation. The ambient air cooled was cooled and humidified based clay pipe evaporative cooing technology. The purpose of the research is to obtain the basic information on the influence of air and water on the heat and mass transfer coefficient for evaporative cooling process through various orientation of clay pipe of aligned and staggered position. Cooler effectiveness, evaporation rate, pressure drop across the test was analyzed. Heat and mass transfer coefficients of experimental values were compared with Coburn [29, 30] heat and mass transfer group. 


\section{EXPERIMENTAL SETUP}

Figure 1 illustrates the main components of the experimental setup which consists of a $3.14 \mathrm{~m}$ length with

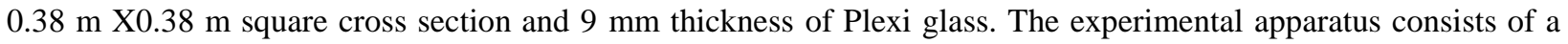
blower, wind tunnel and a matrix of clay pipe, pipes serving as a test section. The wind tunnel has four parts of conical adaptor, straight section, test section and settling section. The first part is a conical adaptor of $0.58 \mathrm{~m} \mathrm{X} 0.58 \mathrm{~m}$ with length $0.60 \mathrm{~m}$ that converts the blower square is connected to second part of the straight section of length $1.5 \mathrm{~m}$ and $0.38 \mathrm{mx} 0.38 \mathrm{~m}$ cross section. The test section of $0.8 \mathrm{~m}$ length is connected in between straight and settling section. The total length of the wind tunnel is $2.5 \mathrm{~m}$ and $0.38 \mathrm{~m} \times 0.38 \mathrm{~m}$ cross section. The photographic view of the experimental set up is shown in Figure 1b.
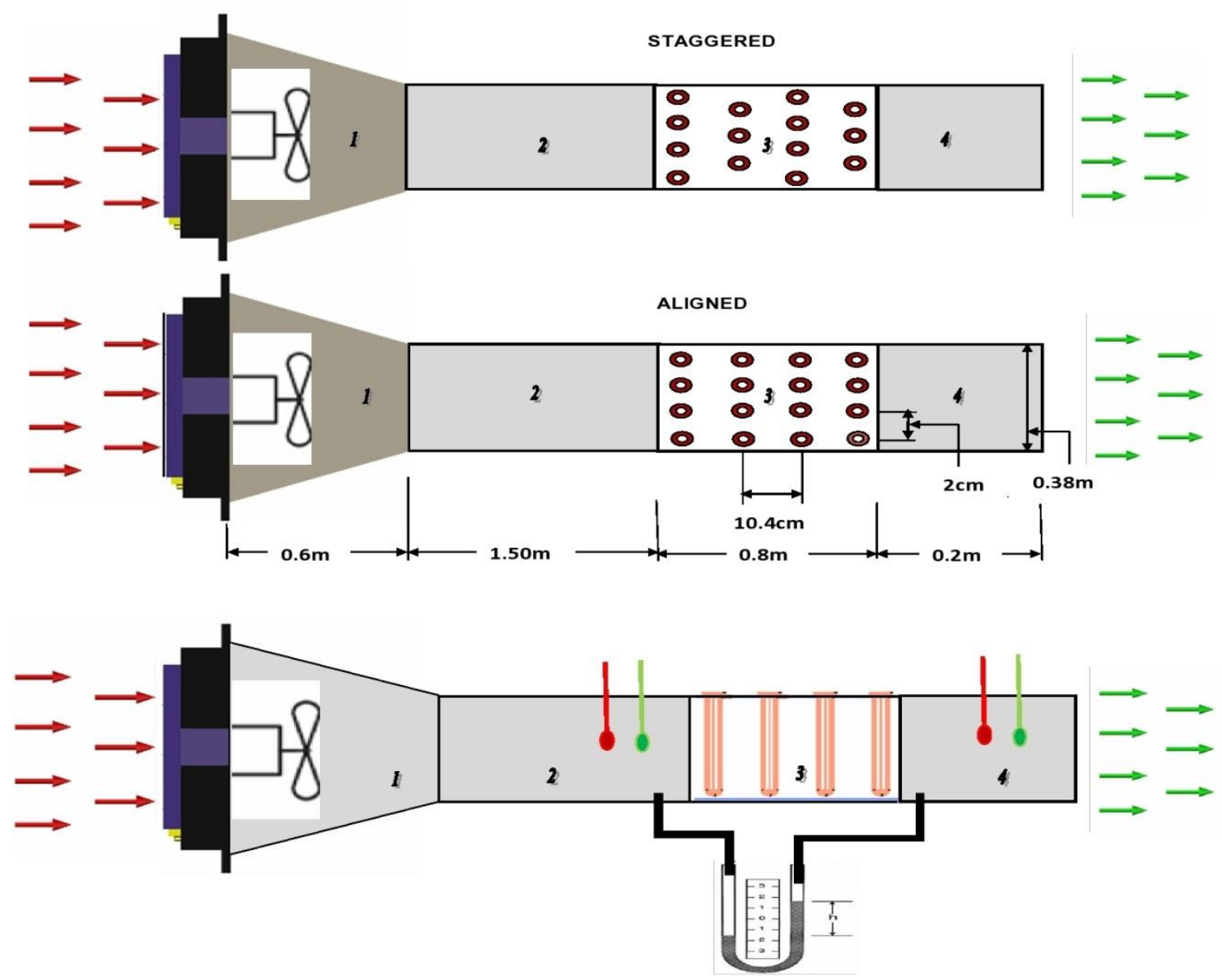

Figure 1a. Schematic diagram of experimental set-up (Top and Front view )

1. Conical adaptor, 2. Straight section, 3. Test section and 4. Settling section. 


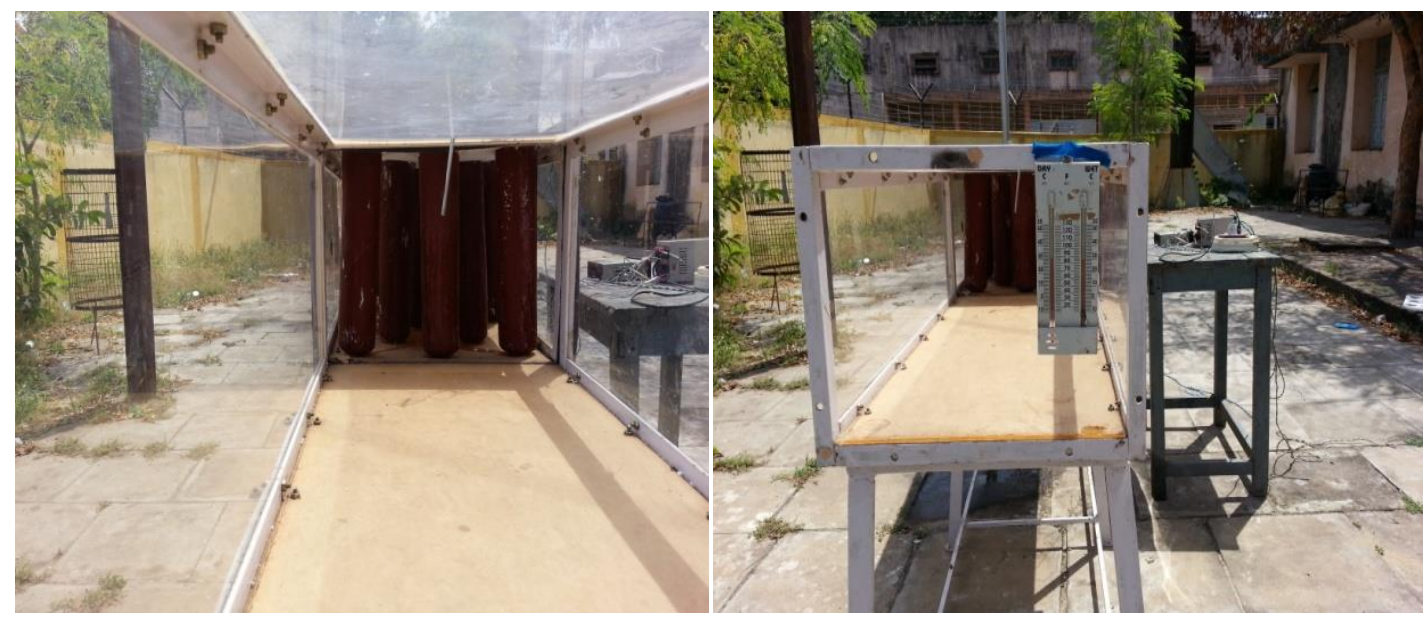

Figure 1b. Photographic view of the experimental setup

In this research, a test section was built with the clay pipes of having different arrangements. The test section is consists of clay pipes arranged as a matrix of cross flow heat exchanger as seen in Figure 2. The clay pipes are arranged in an aligned (16 tubes) and staggered (14 tubes) way with equal distances with respect to air flow direction and it is shown in Figure 2. A square entrance cross section with honey comb flow straightener is used to provide uniform flow of air.
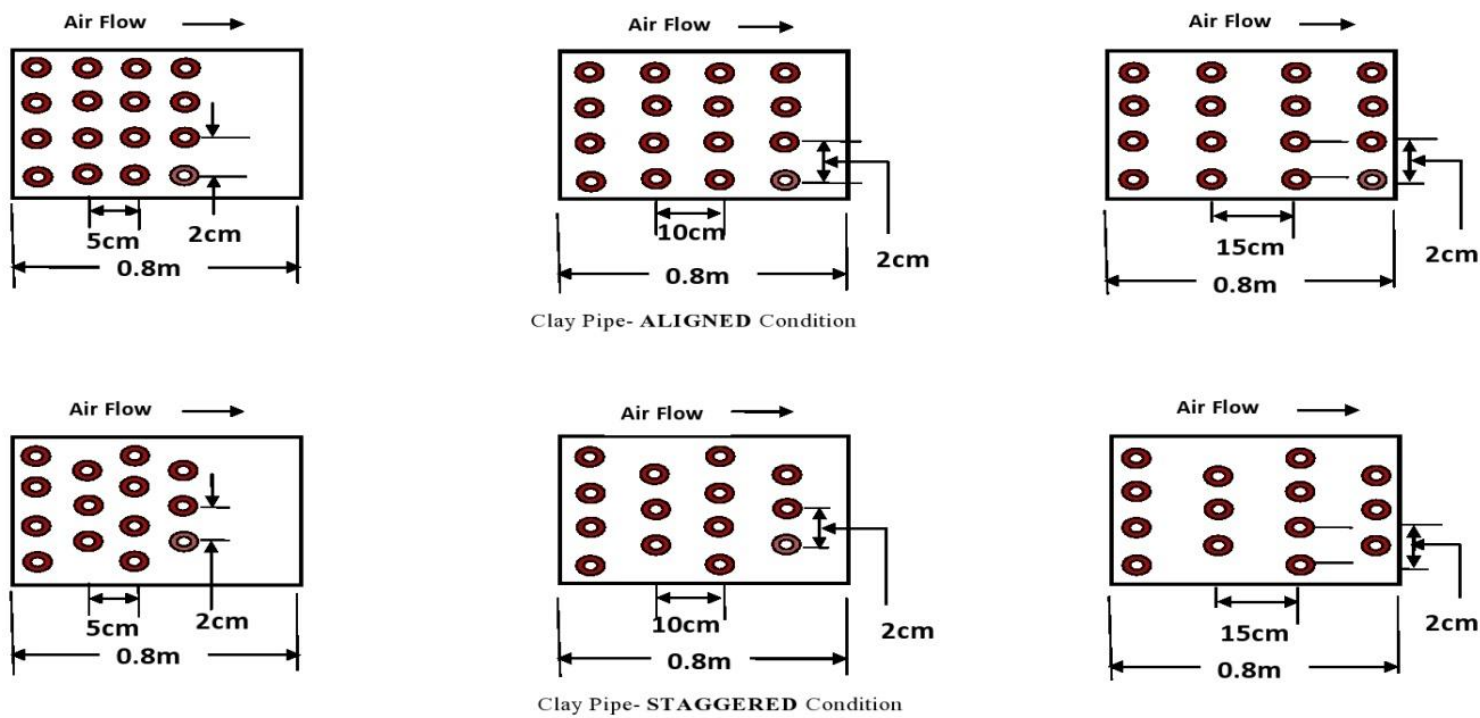

Figure 2. Schematic diagram of the test section in aligned and staggered condition with $5 \mathrm{~cm}, 10 \mathrm{~cm}$ and $15 \mathrm{~cm}$ pitch distance normal to air flow direction

Figure 3 shows the photographic view of the clay pipe diagram. The clay pipe has taken outer diameter as 7 $\mathrm{cm}$ and the length of $40 \mathrm{~cm}$. The clay pipe with different pitch along the air flow direction of $5 \mathrm{~cm}, 10 \mathrm{~cm}$ and $15 \mathrm{~cm}$ are investigate. The air entry side pitches $(2 \mathrm{~cm})$ dimensions of the clay pipes are kept constant. 


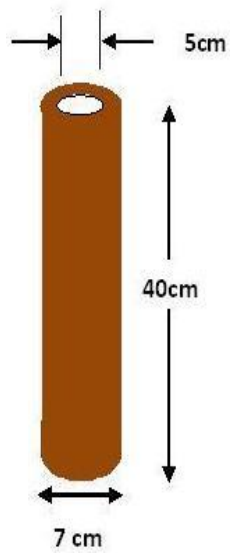

Figure 3. Schematic diagram and photographic view of the clay pipe

As per reference by Riffat and Zhu[18], the clay pipe are made of normal mud used for making water pots which is present in abundant, cheaply available everywhere and easy to use process. It is made from GI sheet die. The evaporative cooler are made from clay material with the chemical composition of $\mathrm{Sio}_{2}(69.39 \%), \mathrm{Al}_{2} \mathrm{O}_{3}(19.23), \mathrm{K}_{2} \mathrm{O}(1.62 \%), \mathrm{Fe}_{2} \mathrm{O}_{3}(0.47), \mathrm{LOI}(6.91 \%)$, etc. The process of manufacture are different and clay pipe with different apparent porosities $(29.7 \%, 32.8 \%$ and $34.6 \%)$ are obtained from firing cycles $(65 \mathrm{hrs}, 5.5 \mathrm{hrs}$ and $4.5 \mathrm{hrs})$ at different temperatures $\left(1020^{\circ} \mathrm{C}, 950^{\circ} \mathrm{C}\right.$ and $\left.810^{\circ} \mathrm{C}\right)$. The porosity is expressed in percentage by volume. It is determined from the amount of water absorbed by the clay pipe.

Inlet and outlet are temperatures are measured at four locations in the experimental setup using copper constant K-Type thermocouple. Two thermocouple are located in the straight and settling section. Four thermocouples are located in the test section inlet and outlet for dry bulb and wet bulb temperature measurements. In addition, 4 thermocouples are used to measure the air temperature drop across the test section and another 4 thermocouples are used to measure water temperature in the clay pipe of aligned and staggered condition. Dry bulb and wet bulb thermometer are used to cross check the air inlet and out temperature. The air and water temperature are recorded and monitored continuously with respect to time by data logging system. Pressure taps are located in the test section entry and exit side to measure the pressure drop across the test section using U-tube manometer. A weighing machined is used to measure the evaporation loss of water in the clay pipes during each run. The clay pipes were measured before and after at each run. The water holding capacity of each clay pipe is $800 \mathrm{ml}$. The unit of measurements and their accuracy are shown in Table.1.

Table 1 Measuring Instruments and their details

\begin{tabular}{|c|c|c|c|c|c|}
\hline $\begin{array}{c}\text { S1 } \\
\text { No }\end{array}$ & Parameter & Instrument & $\begin{array}{c}\text { Unit of } \\
\text { Measurement }\end{array}$ & Accuracy & Range \\
\hline 1 & $\begin{array}{c}\text { Dry Bulb Temperature, } \\
\text { Water Temperature }\end{array}$ & $\begin{array}{c}\text { Copper constant } \\
\text { thermocouples }-\mathrm{K} \text { type }\end{array}$ & ${ }^{\circ} \mathrm{C}$ & $\pm 0.1^{\circ} \mathrm{C}$ & $0-70{ }^{\circ} \mathrm{C}$ \\
\hline 2 & Water Evaporation & Digital balance & $\mathrm{kg}$ & $\pm 0.1 \mathrm{gm}$ & $0-10 \mathrm{~kg}$ \\
\hline 3 & Air Velocity & Vane type anemometer & $\mathrm{m} / \mathrm{s}$ & $\pm 0.1 \mathrm{~m} / \mathrm{s}$ & $0-50$ \\
\hline 4 & Air Pressure Drop & U-tube manometer & $\mathrm{mm}$ of water & $\pm 1 \mathrm{~mm}$ & $0-100 \mathrm{~mm}$ \\
\hline 5 & Relative Humidity & Humidity meter & $\%$ & $\pm 1 \%$ & $0-100 \%$ \\
\hline
\end{tabular}

\section{UNCERTAINTY ANALYSIS}

The objective of a measurement is to determine the value of the measurand, that is, the value of the particular quantity to be measure. A measurement therefore begins with an appropriate specification of the measurand, the 
method of measurement, and the measurement procedure. In general, the result of a measurement is only an approximation or estimate of the value of the measurand and thus is complete only when accompanied by a statement of the uncertainty of that estimate by [34]. Through there are many factors in the measurement uncertainty, in this study, it is assumed that the major factors of resolution or detection of sensors and the variation of the measured data during repeated tests at the test condition. It defined the measurand, the output quantity as a function $Y=f(X)$ of the input quantities $\mathrm{X}$. The uncertainties of the measured data were calculated by combining the type A and B [35].The type A uncertainty was evaluated by statistical analysis of series of observation of the 50 times sampled data and the type B uncertainty was calculated by previous measurements, specifications from the manufacturer, hand-books, calibration certificates, etc. The standard uncertainty was computed as root mean square (RMS) error of the type A and $\mathrm{B}$ uncertainties. Table 2 shows the uncertainty estimation of each measured parameter and 50 samples were collected in each test [35].

At the different test condition, the type uncertainties of the measured parameter would change, and that results in the change of the standard uncertainties. In this study, Monte Carlo simulation (MCS) for the air flow rate, water flow rate were conducted and the results were used to verify the standard uncertainties. In the MCS, commercial software (at Risk-trial version) was used, and the same standard deviation and limits of resolution of sensor of the input variables as previous uncertainty analysis were used. The validation of the standared uncertainty by the uncertainty analysis and the standard deviation by the MCS for the water flow and air flow errors were $0.079 \%$ and $0.043 \%$. Results agree with errors are less than $0.1 \%$ and the errors could be caused by the approximation used in the uncertainty analysis.

Table 2. Uncertainty estimation of variables

\begin{tabular}{|l|l|l|l|l|}
\hline Variables & Unit & A-Type & B-Type & $\mathrm{u}(\mathrm{Y})$ \\
\hline Temperature & ${ }^{\circ} \mathrm{C}$ & 0.015 & 0.01 & 0.012 \\
\hline Water flow meter & $\mathrm{LPH}$ & 0.035 & 0.01 & 0.025 \\
\hline Air Velocity & $\mathrm{m} / \mathrm{s}$ & 1.325 & 0.10 & 0.201 \\
\hline Air Pressure drop & $\mathrm{mm}$ of water & 1.325 & 1.00 & 2.25 \\
\hline
\end{tabular}

\section{HEAT AND MASS TRANSFER ANALYSIS}

In the experimental study, heat and mass transfer between water, clay pipes surface and air was analysed. The heat energy is transferred from air to water through the clay pipe surface and water is evaporated. The heat energy lost from the air is transfer to water and the evaporation of water is given by:

$Q_{T}=Q_{a}+Q_{w}$

$Q_{a}=m_{a} C_{p}\left(T_{d b I / L}-T_{d b o / L}\right)-Q_{w}=h_{e} A\left(T_{m}-T_{w b}\right)$

where $T_{d b I / L}$ and $T_{d b o / L}$ are dry bulb temperature inlet and outlet of the test section. The evaporated heat transfer coefficient is calculated as follows:

$Q_{a}=h_{e} A\left(T_{m}-T_{w b}\right)$

$h_{e}=\frac{Q_{a}}{A\left(T_{m}-T_{w b}\right)}$

$T_{m}=\frac{T_{d b I / L}+T_{d b o / L}}{2}$ 
where $\mathrm{A}$ is the clay pipe surface area, $T_{w b}$ is the wet bulb temperature on the clay pipe surface and $T_{m}$ is the mean temperature.

Heat energy is transferred from air to water by clay pipe surface and heat energy gained by water is represented by:

$Q_{w}=m_{w} C_{w}\left(T_{W I}-T_{w F}\right)$

where $T_{W I}$ and $T_{w F}$ are initial and final temperature of water in the clay pipes.

The transfer of mass and heat during the clay pipe evaporative cooling is described by the following empirical equations.

$N u=\operatorname{Pr}^{m} \operatorname{Re}^{n}$

$S h=a_{1} S c^{m_{1}} R e^{n_{1}}$

In which the coefficient $\mathrm{a}, \mathrm{a}_{1}, \mathrm{~m}, \mathrm{~m}_{1}, \mathrm{n}, \mathrm{n}_{1}$ depend on the properties of the fluid and on the Reynolds number. Mass and heat transfer between the interface of the porous medium, subject to evaporation and an external air flow.

The value of the Reynolds number permits us to determine whether the flow is laminar or turbulent. The velocity through the test section is calculated based on the Reynolds number, and is follows.

$\operatorname{Re}=\frac{\mathrm{DV} \rho}{\mu}=\frac{\mathrm{DV}}{\gamma}$

Here $\mathrm{D}$ is the clay pipe diameter, $\mathrm{V}$ velocity of the fluid, $\rho$ is the density of the fluid and $\mu$ is its dynamic viscosity. It is common to use the kinematic viscosity $\gamma=\mu / \rho$ in defining the Reynolds number.

Nusselt number is defined by:

$\mathrm{Nu}=\frac{\mathrm{h}_{\mathrm{e}} \mathrm{D}}{\mathrm{k}}$

The general correlation for the test section has been formed by Zeitoun et al., and Zhukauskas [20, 29]

$N u=f \times 0.35\left(\frac{P_{1}}{P_{2}}\right)^{0.2} \operatorname{Re}^{0.6} \operatorname{Pr}^{n}\left(\frac{P r}{P r_{s t}}\right)^{0.25}$

From the literature review Kam et al.[28], the flow around the circular tube or pipe is usually laminar when the Reynolds number is below 2,000. In the range 2,000 $<\mathrm{Re}<3,500$, the status of the flow is in transition and for $\mathrm{Re}$ $>3,500$ flow can be regarded as turbulent. The above equation is valid for $1,000 \leq R s \leq 2,00,000$ and $\mathrm{P}_{1}$ and $\mathrm{P}_{2}$ are pitch distance of the clay pipe normal and parallel to test section. $\mathrm{F}$ is the correction factor with test section clay pipe rows less than 16 and $n=0.36$. Based on the reference Zhukauskas [29], the correction factor (f) is 0.95 corresponding to 4 rows and $\left(\frac{P_{1}}{P_{2}}\right) \geq 1$.

The average velocity of the air in the test section is approximately is $1-5 \mathrm{~m} / \mathrm{s}$. The obtained Reynolds number is higher than 3,500, so the flow is turbulent, then use the correlation of Gilliland and Sherwood [30].

The data can be represented in terms of Colburn heat transfer group $\mathrm{J}_{\mathrm{H}}$ by Zhukauskas and Colburn [29,30].

$j_{H}=\frac{f}{2}=S t \operatorname{Pr}^{2 / 3}=\frac{N u}{R e P r^{1-n}}$

$S t=\frac{N u}{R e . P r}$ 
The coefficient of convective heat exchange between the air and clay pipe surface is evaluated from the correlation of Colburn [31], in turbulent flow

$N u_{a}=0.0023 \cdot \operatorname{Re}^{0.8} \cdot \operatorname{Pr}^{0.83}$

$h_{a}=\frac{N u \cdot k_{a}}{D_{o}}$ correlation:

The coefficient of heat transfer between the clay pipe surface and the water is obtained from the following

$N u_{w}=0.57 \cdot G r^{0.25} \cdot \operatorname{Pr}^{0.83}$

$h_{w}=\frac{N u \cdot k_{w}}{D_{i}}$

where, the Grashof number is calculated from the average temperature of clay pipe surface.

There is analogous Colburn $\mathrm{j}$ - factor for mass transfer $\left(\mathrm{j}_{\mathrm{M}}\right)$ defined in a similar manner using the mass transfer coefficient and the Schmidt number by Zeitoun [20].

$j_{M}=\frac{S h}{R e S c^{1-n}}$

where $\mathrm{j}_{\mathrm{M}}$ is the colburn mass transfer group and $\mathrm{S}_{\mathrm{h}}$ is the Sherwood number.

$S h=\frac{h_{m} D}{D_{\gamma}}$

where $\mathrm{h}_{\mathrm{m}}$ mass transfer coefficient and $D_{\gamma}$ is the mass diffusivity of water vapor in air. The Schmidt number (Sc) is:

$S c=\frac{\mu}{\rho D_{\gamma}}$

According to the similarity Sh number can be presented by Kam et al. [28]:

$S h=0.023 \cdot R e^{0.83} S c^{0.33}$

The evaporation rate at the test section can be estimated from:

$m_{e v a}=\frac{Q_{a}}{h_{f g}}$

where $\mathrm{h}_{\mathrm{fg}}$ is the latent heat of vaporization of water and the humidity ratio increased from inlet to outlet of test section and it is obtained from:

$\omega_{O / L}-\omega_{I / L}=\frac{m_{\text {eva }}}{m_{a}}$

The mass transfer coefficient can be obtained from:

$\hat{h}_{m}=\frac{m_{\text {eva }}}{A\left(\omega_{s}-\omega_{m}\right)}$ 
where $\omega_{s}$ is the humidity ratio at the clay pipe surface using psychometric chart by measuring the wet bulb temperature in the clay pipe and $\omega_{m}$ is the average humidity ratio:

$\omega_{m}=\frac{\left(\omega_{I / L}+\omega_{O / L}\right)}{2}$

According to the Zeitoun [20], the convective mass transfer coefficient $\mathrm{h}_{\mathrm{m}}$ is related to the mass transfer coefficient $\hat{h}_{m}$

$h_{m}=\frac{\hat{h}_{m}}{\rho_{a m}}$

where $\rho_{a m}$ is the average air density.

The evaporative cooling and humidification system effectiveness $\varepsilon_{\mathrm{c}}$ and $\varepsilon_{\mathrm{h}}$ at the test section are represented by Mohamed Ali et.al [32]:

$\varepsilon_{c}=\frac{\left(T_{d b I / L}-T_{d b o / L}\right)}{\left(T_{d b I / L}-T_{w b I / L}\right)}$

$\varepsilon_{h}=\frac{\left(\omega_{O / L}-\omega_{I / L}\right)}{\left(\omega_{W I / L}-\omega_{I / L}\right)}$

where the $\omega_{w I / L}$ is the specific humidity using the water temperature at $100 \%$ relative humidity.

\section{RESULTS AND DISCUSSION}
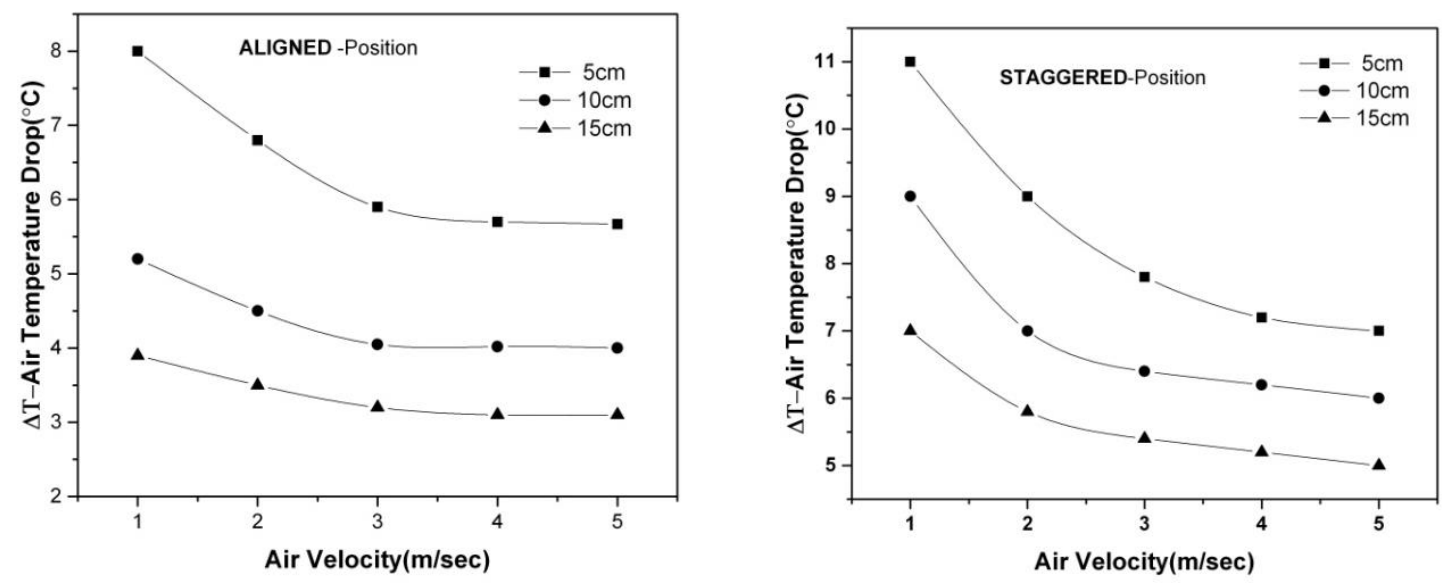

Figure 4. Average air temperature drop across the test section for different air volumetric flow rates of aligned and staggered position.

Figure 4 shows the average air temperature different between inlet and out let of the test section of the clay pipe against the air velocity of $1 \mathrm{~m} / \mathrm{s}-5 \mathrm{~m} / \mathrm{s}$. The test portion of the clay pipes are arranged in aligned and staggered position with pitch distance of $5 \mathrm{~cm}, 10 \mathrm{~cm}$ and $15 \mathrm{~cm}$ along the normal air flow direction. The clay pipe cooling effect is associated with the temperature drop across the test section due to both forced convective heat and mass transfer between clay pipes and flowing air. Based on the temperature drop, the cooling effect is more at low air flow rate (1 $\mathrm{m} / \mathrm{s}$ ) for both aligned and staggered position. The temperature drop is achieved $8^{\circ} \mathrm{C}$ and $11^{\circ} \mathrm{C}$ for both positions at $1 \mathrm{~m} / \mathrm{s}$. At higher air velocity, the retention time of contact between air and clay pipes surface contact is less. So a certain 
amount of air will pass by without contact the clay pipes, which lead to a drop in water evaporation. This results agree with Al-Fahed et al. [22] reference that at low air velocity of $1 \mathrm{~m} / \mathrm{s}$ the temperature gradient is high for both aligned and staggered position and it decreases when air velocity increases.
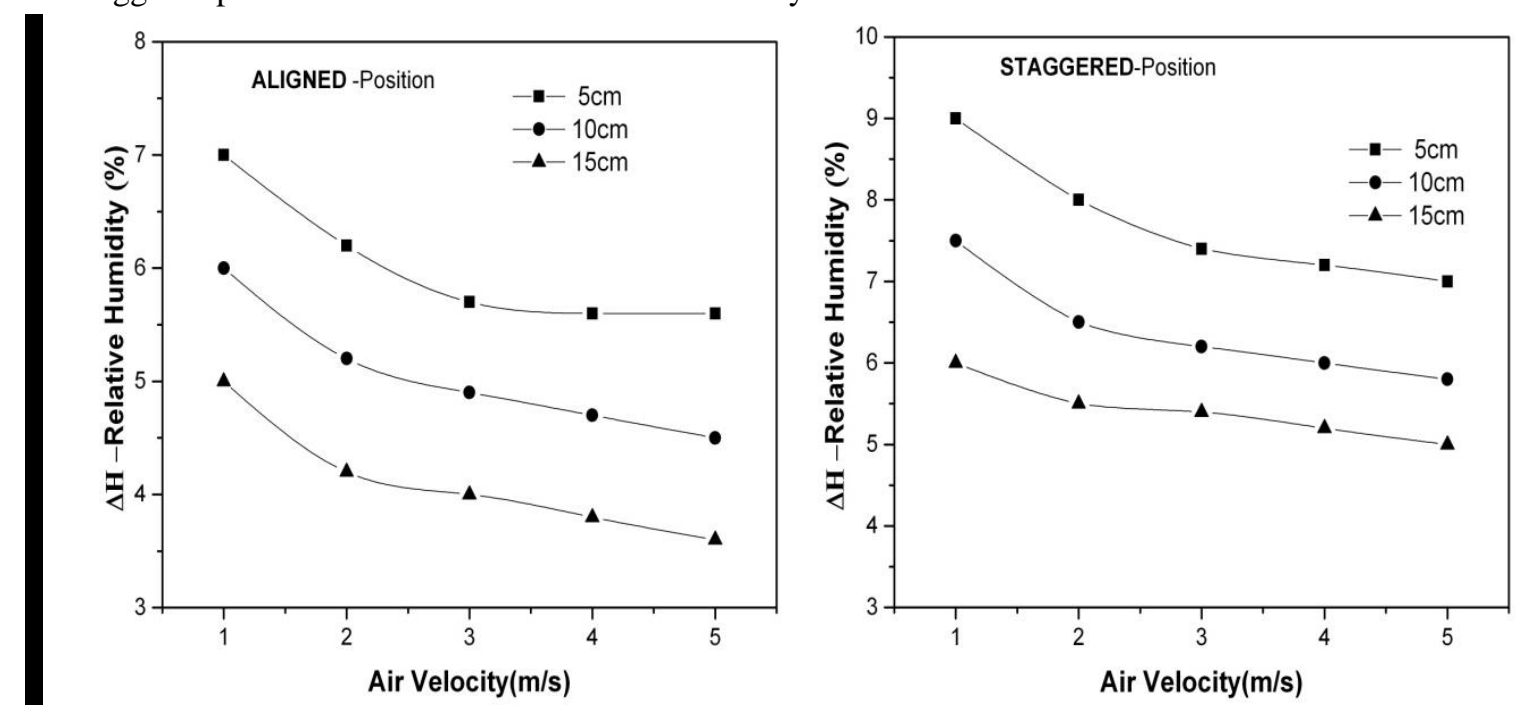

Figure 5. Average variation of relative humidity across the test section for different air volumetric flow rates of aligned and staggered position.

As shown Figure 5, shows variation of relative humidity versus different air velocity across the test section in aligned and staggered position of clay pipes. It can be seen that the variation of relative humidity decreases with increasing the air velocity. As can be noticed from these figure, in both types of clay pipe position with increasing the pitch distance $(5 \mathrm{~cm}, 10 \mathrm{~cm}$ and $15 \mathrm{~cm})$ the variation of humidity decreases. Increasing humidity variation with decreasing pitch distance is due to quick contact between wetted clay pipe surface areas and the flowing air. 7\% and $9 \%$ relative humidity variations were achieved in aligned and staggered position at $1 \mathrm{~m} / \mathrm{s}$ air velocity. Variation relative humidity is more at staggered position compared aligned due to air passes over all the posts surfaces. From the graph, staggered positions have highest relative humidity variation compare with aligned one with pitch distance $1 \mathrm{~m} / \mathrm{s}$. Since minimum pitch distance provides immediate contact between air and pot surface area and increases heat and mass transfer between air water, the variation of relative humidity improves. Moreover, smaller pitch distance provides small air passageway in evaporative cooler. In addition, results indicated that the change in relative humidity at low values of air speed is relatively greater than for the high-speed case, and that is due to the phenomenon of a high evaporation rate at high speed. 

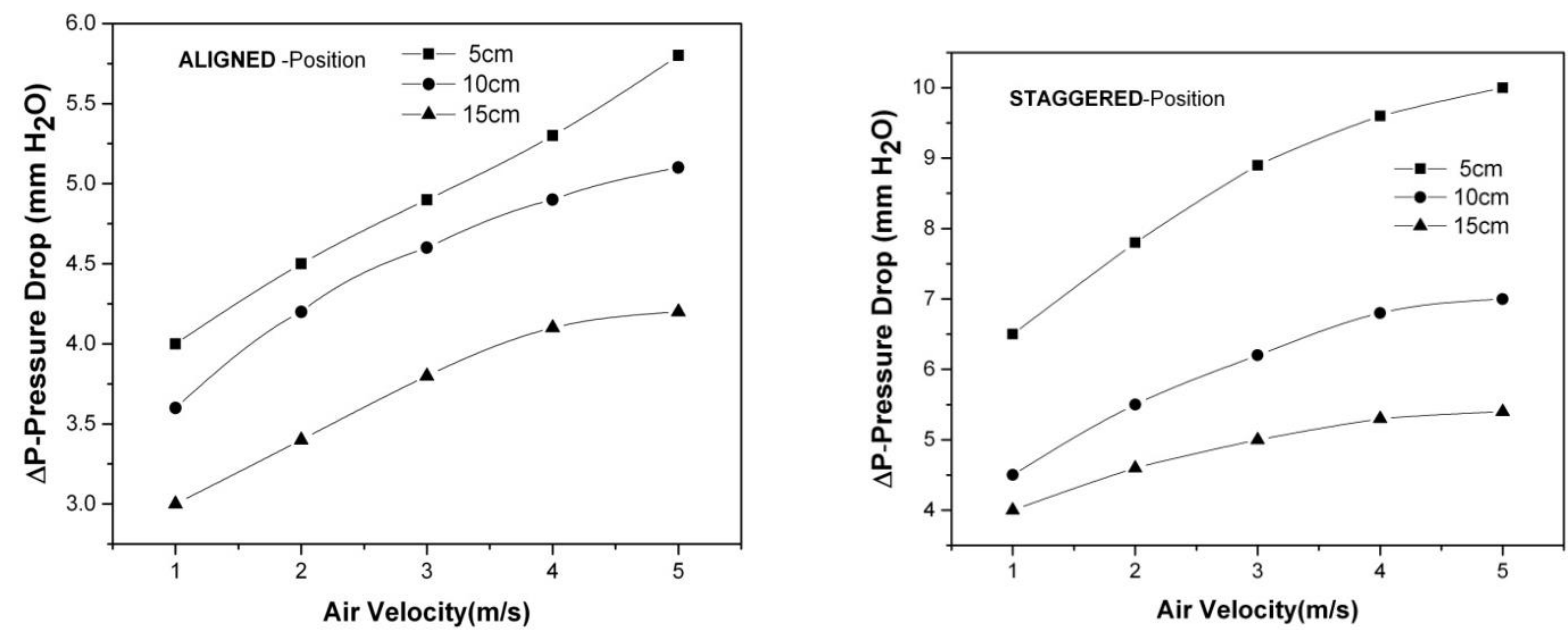

Figure 6. Average variation of pressure drop across the test section for different air volumetric flow rates of aligned and staggered position.

Figure 6 shows the effects of pitch distance and air velocity on the average pressure drop along the test section for aligned and staggered arrangements of the evaporative cooler. As expected, the pressure drop increases by increasing the inlet air velocity in both types of arrangements. The reason is that increasing inlet air velocity will lead to higher maldistribution of flow field at inlet of the test section as well as higher air resistance between clay pipes. It can also be seen that with decreasing the pitch distance, the pressure drop across test section increases. This is due to higher resistance of the flowing air across the clay pipes. Another important result that can be obtained from the figure is that at a same pitch distance and inlet air velocity, the pressure drop in staggered position is higher than that of aligned position. From the experiments results, generally greater pressure drop are obtained with smaller pitch distance of the clay pipes. In our study the staggered position pressure drop is higher when compared with aligned position. It is due to many reasons that the structure, orientation, physical properties, porosities, water holding capacity and air velocity. The staggered position can be found higher pressure drop since these have small air passage therefore air resistance happened so air passes through section very slowly. The aligned position can be found lowest pressure drop since these have largest air passage way therefore air passes through the section highly with low air resistance. This is due to the large path size in a unit area for aligned position which leads to smaller contact area and smaller path size with higher contact area and consequently higher friction with respect to staggered position. 

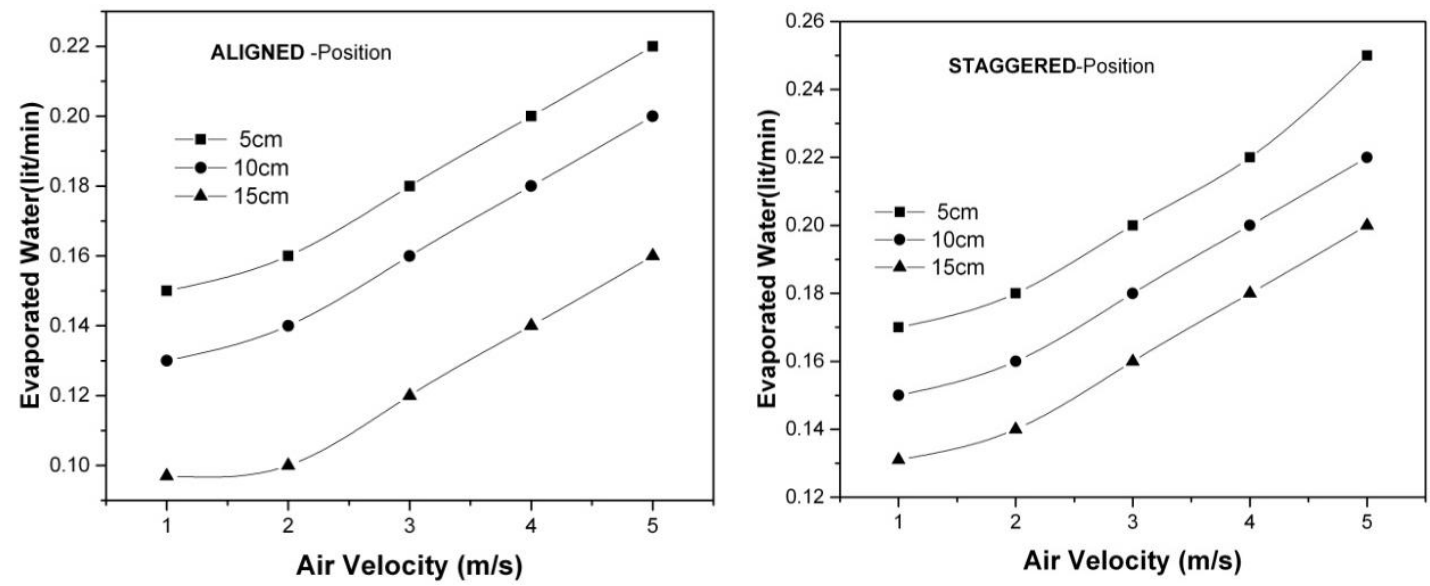

Figure 7. Effect of evaporation rate of water across the test section for different air velocity in aligned and staggered position.

In Figure 7 the amount of evaporated water for different air velocity and pitch distance of the clay pipe evaporative cooler. From the figure, it is evident that with increasing the pitch distance the amount of evaporated water decreases. It is due to the fact that increasing the pitch distance leads to decreasing the contact surfaces between clay pipes and the flowing air. Moreover, with increasing the inlet air velocity the amount of evaporated water increases. With increasing the inlet air velocity, the mass transfer coefficient on the surfaces of clay pipes increases which leads to higher amount of evaporated water. In this study more amounts was evaporated $0.22 \mathrm{lit} / \mathrm{min}$ and $0.25 \mathrm{lit} / \mathrm{min}$ for aligned and staggered position at $5 \mathrm{~m} / \mathrm{s}$. Al-Fahed et al. [22] mentioned that water consumption is an important economic factor in this novel experimental work. In the experimental study, good performance of evaporative cooling is obtained at lower air velocity of $1 \mathrm{~m} / \mathrm{s}$ for both positions with lower water evaporation. Looking at Figure 7, the value of water consumption is seen be small. For example, at an air flow rate of $1 \mathrm{~m} / \mathrm{s}$, the evaporation rate of water are $0.15 \mathrm{lt} / \mathrm{min}$ and $0.17 \mathrm{lt} / \mathrm{min}$ for aligned and staggered position, which is considered to be a low value. Results indicate that water consumption for the aligned arrangement is less than the staggered case. For both arrangements, water consumption decreases with the increase of pitch distance. As expected, as the air velocity increases, more evaporation occurs; hence, an increase in water consumption is noticed. 

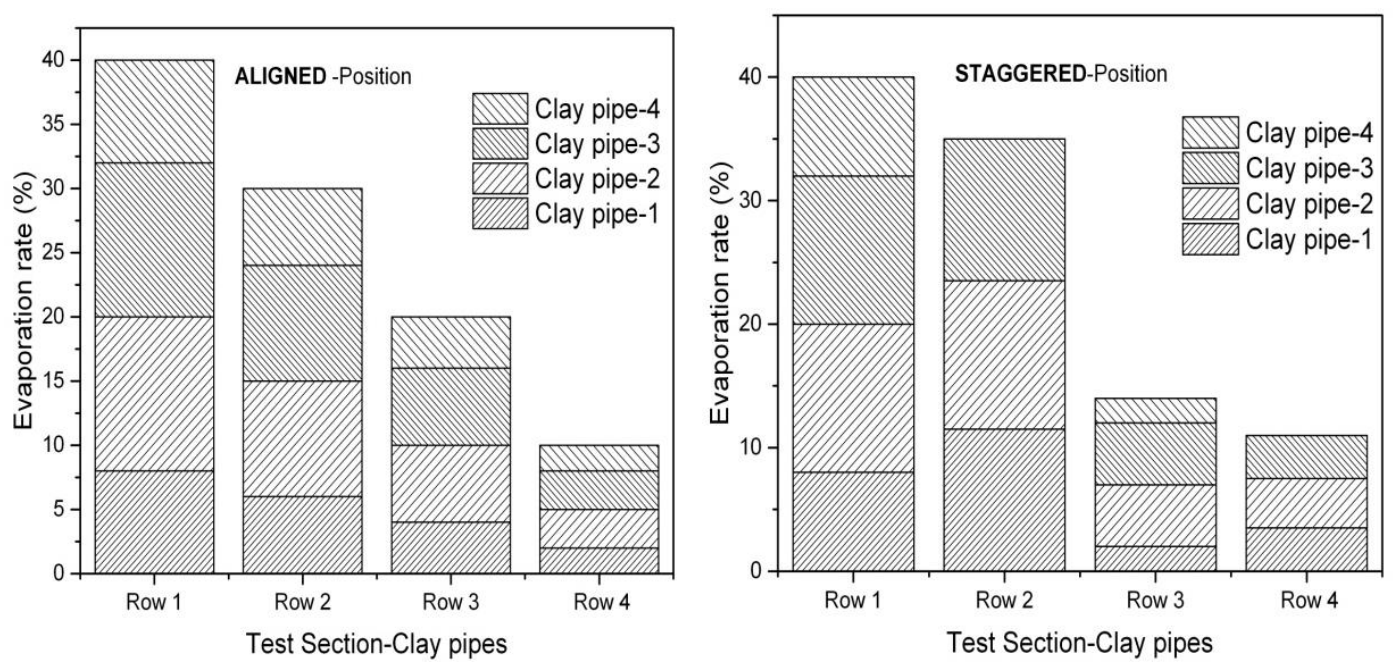

Figure 8. Evaporation rate of water in each row of the test section in aligned and staggered conditions

From Figure 8, shows that more amount of water is evaporated from the first row of the test section of aligned and staggered position. For the both position, $40 \%$ of water is evaporated. Particularly clay pipe 2 and 3 has more evaporation accrued in the first and third row of the clay pipes. It is due to more amount of air is conduct over the surface comparing with 1 and 4 tubes. Similarly staggered position second row pipes evaporated $36 \%$ compared with $30 \%$ in aligned position. It is due to air contact the second row pipes directly from the first row pipes. The evaporation rate is drastically reduced from the first row to fourth row of the clay pipes due moisture absorption rate. At the entry level moisture abortion rate increased from the clay pip surface and it is drastically reduced due to saturation of the air.
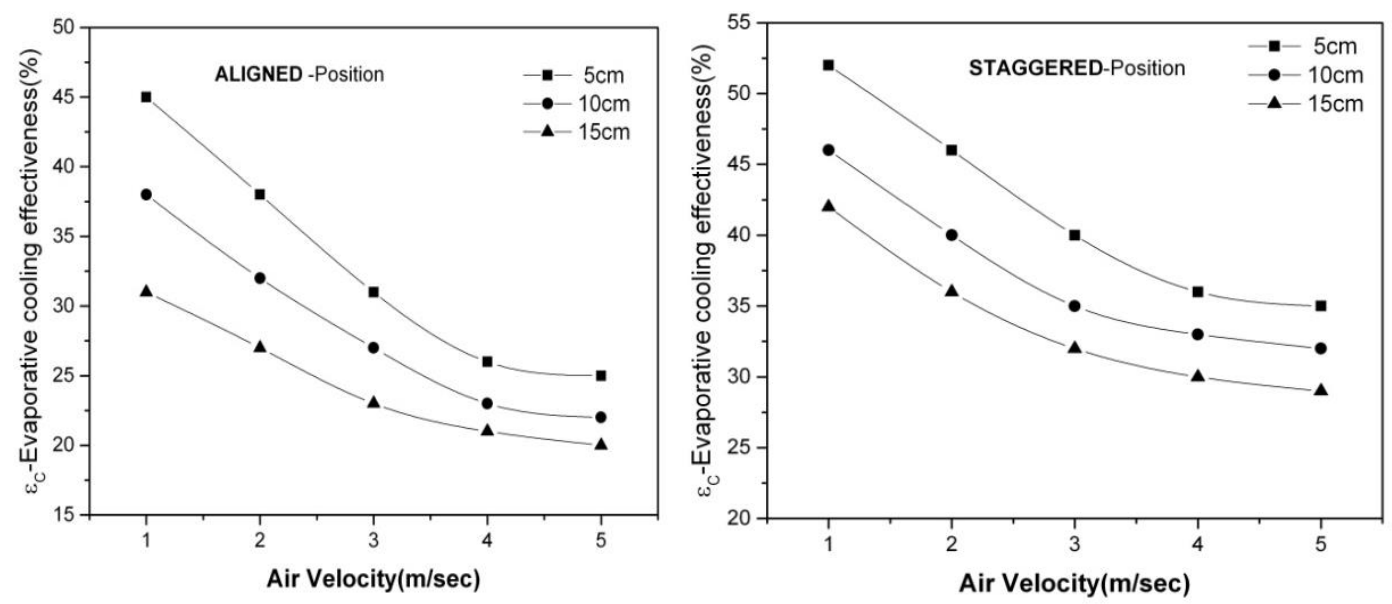

Figure 9. Evaporative cooling effectiveness across the test section for different air velocity rates of aligned and staggered position. 

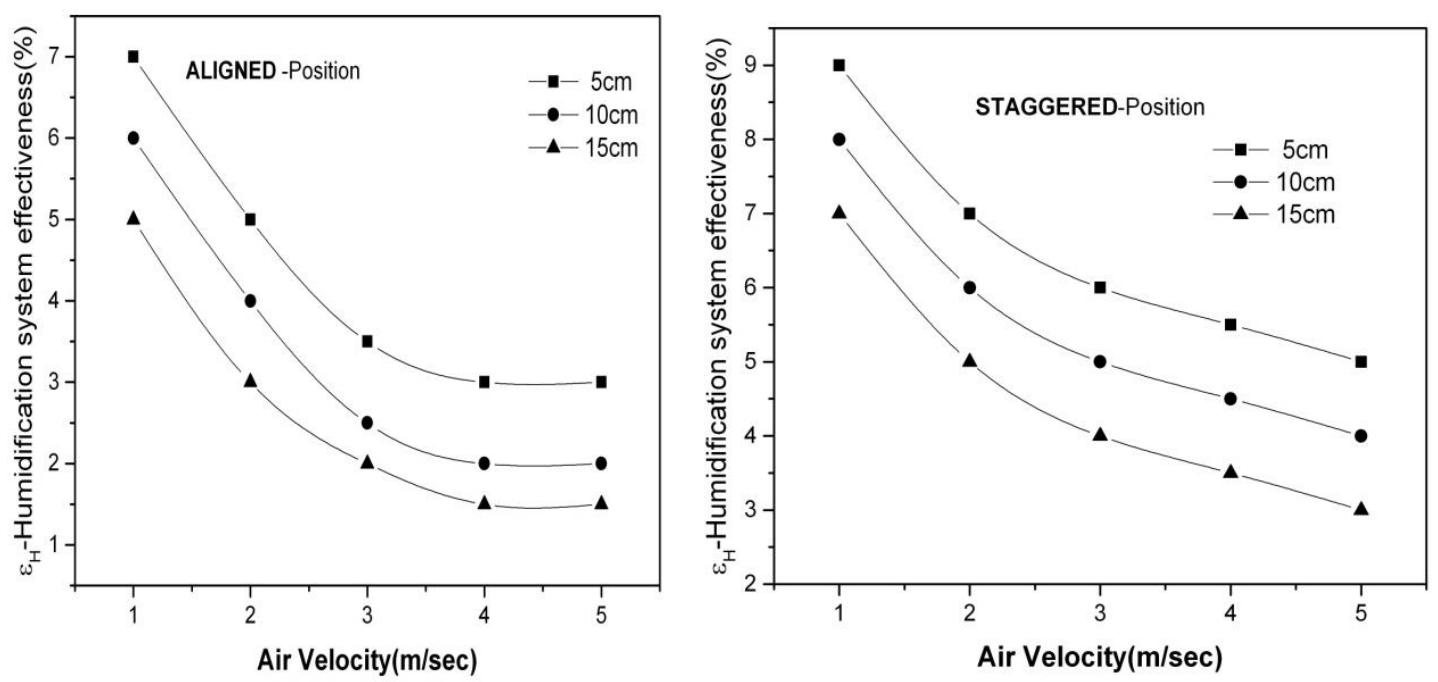

Figure 10. Humidification system effectiveness across the test section for different air volumetric flow rates of aligned and staggered position.

Figure 9 and 10 show the performance of the clay pipe evaporative cooler in aligned and staggered position of experimental data at the test section using the evaporative cooling and humidification system effectiveness $\varepsilon_{\mathrm{c}}$ and $\varepsilon_{\mathrm{H}}$ respectively using Eq. (27) and (28). With increasing the inlet air velocity from 1 to $5 \mathrm{~m} / \mathrm{s}$, cooler effectiveness decreased for both position. Similarly cooler effectiveness is decreased by increasing the clay pipe pitch distance. It is due to less heat and mass transfer between air to water and high pressure drop occurs at higher air velocity. The retention time is high at lower velocity of air and large frontal area of the clay pipe. From this graph, the pitch distance decreases with increase effectiveness. The results show that aligned and staggered position have the highest efficiency of $45 \%$ and $53 \%$ for $1 \mathrm{~m} / \mathrm{s}$ air velocity. Similarly humidity system effectiveness increases at lower air velocity. It can be observed that the cooling efficiency increases as the air velocity decreases, because slower air velocity causes greater evaporation rate as air passes more time through the clay pipe evaporator cooler. Also by increasing the air velocity the available time for heat and mass transfer between air and water decreases. From Figures 9 and 10, the air velocity has inversely proportional to evaporative cooling and humidification system effectiveness. The air passes through the clay pipe evaporative cooler, its temperature decreases and, relative humidity increases. 

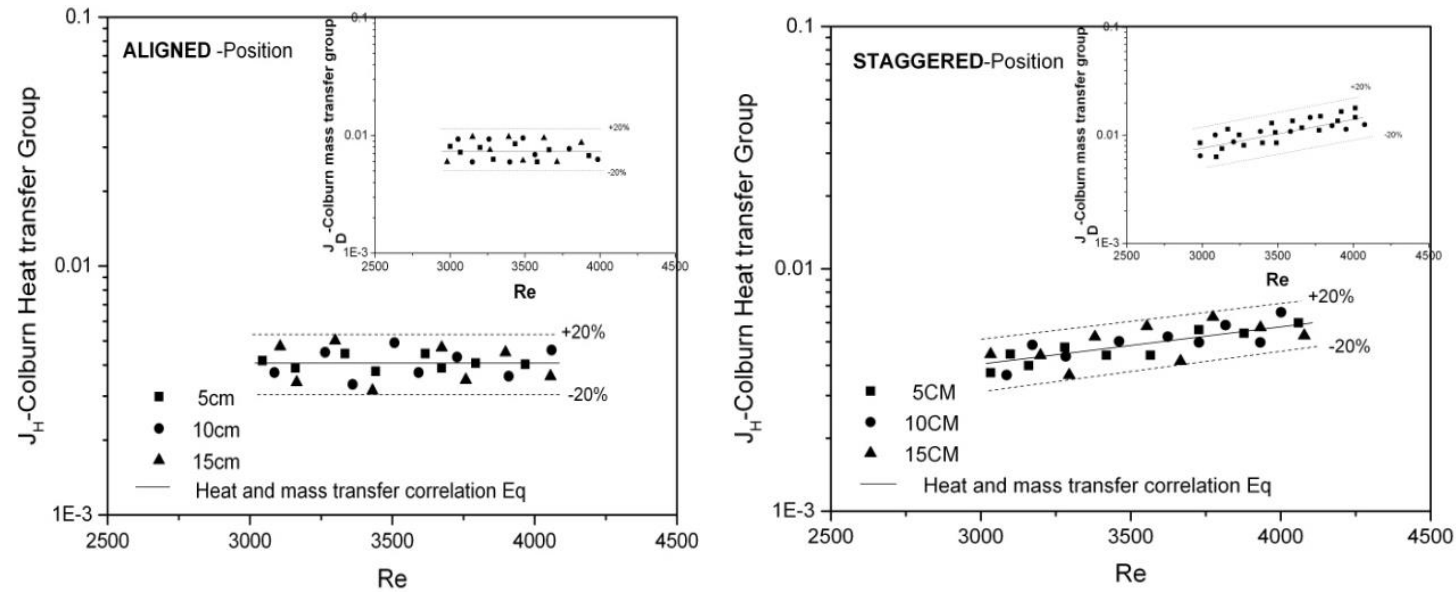

Figure 11. Comparision of experimental vlues with Colburn heat and mass transfer groups $\left(\mathrm{J}_{\mathrm{H}}\right.$ and $\left.\mathrm{J}_{\mathrm{M}}\right)$ for aligned and staggerd conditions.

Comparison of the experimental data of the aligned and staggered position of the clay pipes heat and mass transfer coefficients were compared with Colburn heat and mass transfer $\left(\mathrm{j}_{\mathrm{H}}\right.$ and $\mathrm{j}_{\mathrm{M}}$ ) group using Eq. (8) and Eq. (9). The experimental data show good agreement with Colburn equations and they lie within $\pm 20 \%$ and it is shown in Figure 11.

\section{CONCLUSIONS}

The aim of the research is to investigate the underlying mechanical, thermodynamic and heat transfer phenomena of clay pipe evaporative cooler in a wind tunnel. Results showed that using clay pipe arrangement of both orientations enhances the heat transfer between air and the clay pipe surface.

- Particularly staggered position demonstrates high air temperature drop compared to align one. For staggered position air temperature drop was $11^{\circ} \mathrm{C}(5 \mathrm{~cm}$ pitch $), 9^{\circ} \mathrm{C}(10 \mathrm{~cm}$ pitch $)$ and $7^{\circ} \mathrm{C}(15 \mathrm{~cm}$ pitch $)$ at $1 \mathrm{~m} / \mathrm{s}$ air velocity.

- Much greater pressure drop was accrued in the $5 \mathrm{~cm}$ pitch compared to $10 \mathrm{~cm}$ and $15 \mathrm{~cm}$ pitch distance.

- At lower air velocity of $1 \mathrm{~m} / \mathrm{s}$ with $5 \mathrm{~cm}$ pitch distance, the relative humidity is $9 \%$ and $7 \%$ for staggered and aligned condition.

- The heat and mass transfer coefficient of experimental value are compared with Colburn heat transfer group and it is within the limit of $20 \%$.

- The maximum evaporative cooling effectiveness is $45 \%$ and $53 \%$ in aligned and staggered position at $1 \mathrm{~m} / \mathrm{s}$ air velocity. 


\section{ACKNOWLEDGMENT}

The authors thank the authorities of Annamalai University, Annamalai Nagar, Tamil Nadu, India, for the facilities provided to conduct the experiment in the steam laboratory in the Department of Mechanical Engineering for the research work.

\section{NOMENCLATURE}

A Clay pipe surface area $\left(\mathrm{m}^{2}\right)$

$\mathrm{C}_{\mathrm{w}} \quad$ Specific heat of water $(\mathrm{J} / \mathrm{kg} \mathrm{K})$

$\mathrm{C}_{\mathrm{P}} \quad$ Specific Heat of air at constant Pressure $(\mathrm{J} / \mathrm{kg} \mathrm{K})$

D $\quad$ Clay pipe diameter (m)

$D_{\gamma} \quad$ Mass diffusivity $\left(\mathrm{m}^{2} / \mathrm{s}\right)$

f Correction Factor

$\mathrm{Gr} \quad$ Grasoh of number

$h_{e} \quad$ Heat transfer coefficient $\left(W / m^{2} \mathrm{~K}\right)$

$\mathrm{h}_{\mathrm{fg}} \quad$ Latent heat of vaporization $(\mathrm{J} / \mathrm{kg})$

$\mathrm{h}_{\mathrm{m}} \quad$ Convective Mass transfer coefficient $(\mathrm{m} / \mathrm{s})$

$\hat{h}_{m} \quad$ Mass transfer coefficient $\left(\mathrm{kg} / \mathrm{m}^{2} \mathrm{~s}\right)$

$\mathrm{J}_{\mathrm{M}} \quad$ Colburn mass transfer group

$\mathrm{J}_{\mathrm{H}} \quad$ Colburn heat transfer group

k Thermal Conductivity(W/m K)

$\mathrm{m} \quad$ Mass flow rate $(\mathrm{kg} / \mathrm{s})$

$m_{\text {eva }} \quad$ Evaporation rate $(\mathrm{kg} / \mathrm{s})$

$\mathrm{Nu} \quad$ Nusselt number

$\mathrm{P}_{1} \quad$ Pitch distance of clay pipe normal to the flow (m)

$\mathrm{P}_{2} \quad$ Pitch distance of the clay pipe parallel to the flow (m)

Pr Prandtl number

$\mathrm{Pr}_{\mathrm{st}} \quad$ Prandtl number at clay pipe surface

Q Heat transfer (W)

Re Reynolds number

Sc Schmidt number

Sh Sherwood number

St Stanton number

$\mathrm{T} \quad$ Temperature $\left({ }^{\circ} \mathrm{C}\right)$

V Velocity $(\mathrm{m} / \mathrm{s})$

\section{Greek symbols}

$\rho \quad \operatorname{Density}\left(\mathrm{kg} / \mathrm{m}^{3}\right)$

$\rho_{a m} \quad$ Average air density $\left(\mathrm{kg} / \mathrm{m}^{3}\right)$

$\mu \quad$ Dynamic Viscosity $(\mathrm{kg} / \mathrm{ms})$

$\gamma \quad$ Kinematic Viscosity $\left(\mathrm{m}^{2} / \mathrm{s}\right)$

$\omega \quad$ Humidity ratio $(\mathrm{kg} / \mathrm{kg}$ of dry air)

\section{Subscripts}

$\begin{array}{ll}\mathrm{a} & \text { Air } \\ \mathrm{db} & \text { Dry bulb } \\ \mathrm{F} & \text { Final } \\ \mathrm{i} & \text { Inner } \\ \mathrm{I} & \text { Initial } \\ \mathrm{I} / \mathrm{L} & \text { Inlet } \\ \mathrm{m} & \text { Mean }\end{array}$


Journal of Thermal Engineering, Research Article, Vol. 3, No. 2, pp. 1163-1180, April, 2017

$\begin{array}{ll}\text { o } & \text { Outer } \\ \text { O/L } & \text { Outlet } \\ \text { st } & \text { Surface temperature } \\ \text { T } & \text { Total } \\ \text { w } & \text { Water } \\ \text { wb } & \text { Wet bulb }\end{array}$

\section{REFERENCES}

[1] R. M. Lazzarin, Introduction of a simple diagram-based method for analyzing evaporative cooling, Applied Thermal Engineering. 27(2007) 2011-2025.

[2] M. Lain, J. Hensen, Combination of low energy and mechanical cooling technologies for buildings in central Europe, 5th International Refrigeration and Air Conditioning Conference, France, (2004) 1-6.

[3] R.S .Gates, J.L. Usry, J.A. Nienaber, An optical misting method for cooling livestock housing, Transaction of ASAE. 34(5) (1991) 2199-2206.

[4] M. Santamouris and D.N. Asimakopoulos, Passive Cooling of Buildings, James \& James Science Publishers Ltd., London, (1996) Ch.9 220-301.

[5] S. K. Abbouda, E. A. Almuhanna, Improvement of Evaporative Cooling System Efficiency in Greenhouses, International Journal of Latest Trends in Agriculture \& Food Sciences.( 2012) 2(2) 83-89.

[6] A.K.Joudi, M.S. Mehdi, Application of Indirect Evaporative Cooling to Variable Domestic Cooling Load, Energy Conversion \& Management. 41(2000) 1931-1951.

[7] M. Al-asad, T. Emtairah, Cities and Buildings, Report of the Arab Forum for Environment and Development (AFED), Beirut, Ch-6 (2011) 161-204.

[8] Catharine Harris, Anti-inhalant Abuse Campaign Targets Building Codes: 'Huffing' of Air Conditioning Refrigerant a Dangerous Risk. The Nation's Health. American Public Health Association, 2010.Web. 05 Dec. 2010.

[9] B. Riangvilaikul, S. Kumar, An experimental study of a novel dew point evaporative cooling system. Energy and Buildings.42 (2010) 637-644.

[10] K. Daou, R. Z. Wang, Z.Z. Xia, Desiccant cooling air conditioning: a review, Renewable and Sustainable Energy Reviews. 10(2) (2004) 55-77.

[11] A.K.Joudi, M.S. Mehdi, 2000, Application of Indirect Evaporative Cooling to Variable Domestic Cooling Load, Energy Conversion \& Management, 41(2000) 1931-1951.

[12] R.K.Suri, 2001, Energy-Saving Potential of an Indirect Evaporative Cooler, Applied Energy. 69(1) (2001) 69-76.

[13] B. Costelloe, D. Finn, 2003, Indirect Evaporative Cooling Potential in Air-Water System in Temperature Climates, Energy and Buildings, 35 (2003) 573-591.

[14] A.Gasparella, G.A. Longo, 2003, Indirect Evaporative Cooling and Economy Cycle in Summer Air Conditioning, International Journal of Energy Research, 27(7) (2003) 625-637.

[15] E. Ibrahim, L. Shao, S. B. Riffat, Performance of Porous Ceramic Evaporators for Building Cooling Application, Energy Build.35(2003) 941-949.

[16] S. Loeb, Membrane evaporative cooling to $30^{\circ} \mathrm{C}$ or less:1. Membrane evaporative cooling of contained water, Annals of the New York Academy of Sciences. 984(2003) 515-527.

[17] D.W.Johnson, C.Yavuzturk, J.Pruis, Analysis of heat and mass transfer phenomena in hollow fiber membranes used for evaporative cooling, Journal of Membrane Science. 227(1-2) (2003) 159-171.

[18] S. Riffat, J. Zhu, Experimental investigation of an indirect evaporative cooler consisting of a heat pipe embedded in porous ceramic, The Journal of Engineering Research. 1 (2004) 46-52.

[19] Meryem Kanzari, Rabah Boukhanouf, Hatem G. Ibrahim, Mathematical Modeling of a Sub-Wet Bulb Temperature Evaporative Cooling Using Porous Ceramic Materials, International Journal of Chemical, Materials Science and Engineering. 7(12) (2013) 17-23.

[20] O. Zeitoun, M. Ali, H. Al-Ansary, A. Nuhait, Ceramic tubes membrane technology as a new humidification technique for gas turbine inlet air cooling, International journal thermal science.80(2014) 1-10. 
Journal of Thermal Engineering, Research Article, Vol. 3, No. 2, pp. 1163-1180, April, 2017

[21] S. Wanphen, K. Nagano, Experimental study of the performance of porous materials to moderate the roof surface temperature by its evaporative cooling effect, Building and Environment. 44(2) (2009) 338-351.

[22] S. F. Al-Fahed, F. N. Alasfour, M. M. A. Quadri, Pottery evaporative cooling system: a novel approach to cool inlet air with minimal change in relative humidity and low water consumption, Experimental Heat Transfer. 27(2014) 144-159.

[23] W. Chen, Thermal Analysis on the Cooling Performance of a Wet Porous Evaporative Plate for Building, Energy Conversion Management. 52(2011) 2217-2226.

[24] Ashutosh Mittal, Tarun Kataria, Gautam K. Das, Siddharth G. Chatterjee, Evaporative cooling of water in a small vessel under varying ambient humidity, International Journal of Green Energy, 3(2006) 347-368.

[25] V.O.Aimiuwu, Evaporative cooling of water in hot arid regions, Energy Conversion and Management. 33(1) (1992) 69-74.

[26] V.O.Aimiuwu, Ceramic storage system based on evaporative cooling. Energy Conversion and Management. 34(8) (1993) 707-710.

[27] E.E.Anyanwu, (2004). Design and measured performance of a porous evaporative cooler for preservation of fruits and vegetables, Energy Conversion and Management. 45(2004) 2187-2195.

[28] S. Kam, M. Zongo, B. Dianda, A. Konfe, D.J.Bathiebo, L.Aurelien, Study of hygrothermal transfer through porous clay tubes application to the cooling of water volume in the sahelian zone, Advances in Applied Science Research. 3 (4) (2012) 2090-2102.

[29] A. Zhukauskas, Heat transfer from tubes in cross flow, in: J.P. Hartnett, T.F. Irvine Jr. (Eds.), Advances in Heat Transfer. vol. 8Academic Press, New York, (1972) 458-464.

[30] E.R.Gilliland, T.K. Sherwood, Diffusion of vapors into air stream, Ind. Eng. Chem.26(5) (1934) 516-523.

[31] A.P. Colburn, A method of correlating forced convection heat transfer data and a comparison with fluid friction, Trans. AICHE. 29(1933) 174-210.

[32] Mohamed Ali., Obida Zeitoun., Hany Al-Ansary., and Abdullah Nuhait., Humidification technique using new modified mini module membrane contactors for air cooling, Advance Mechanical Engineering.5(2013) 1-11.

[33] P. J. Erens, A. A. Dreyer, Modeling of Indirect Evaporative Air Coolers, Int. J. Heat Mass Transf. 36(1993) 17-26.

[34] Persson, C. G., Guide to the Expression of Uncertainty in Measurement (GUM) and its Possible Use in Geo Data Quality Assessment, Q-KEN, Riga, 2011.

[35] Lee, J., et al., Uncertainty Analysis and ANOVA for the Measurement Reliability Estimation of Altitude Engine Test, Journal of Mechanical Science and Technology, 21(4) (2007), 664-671. 